\title{
Effects of temperature on individual growth rate and body size of a freshwater amphipod
}

\author{
Vadim E. Panov and Donald J. McQueen
}

\begin{abstract}
Individual growth rates of the freshwater amphipod Hyalella azteca (Saussure) were measured in the littoral zone of two small oligotrophic Ontario lakes and in growth experiments over a natural temperature gradient $\left(10,15,20\right.$, and $\left.23^{\circ} \mathrm{C}\right)$. Field observations showed that a temperature of $20^{\circ} \mathrm{C}$ is important for both the induction and termination of reproductive resting stages in H. azteca. Growth rates were more affected by temperature in small than in large individuals. Growth parameters are related to rearing temperature by linear regressions, which can be used as a simple model for bioenergetics calculations in crustaceans. A negative relationship between water temperature and maximum size attained by the amphipods was found. The largest adults were absent in studied populations when summer temperatures were high, and this phenomenon, which has also been observed in other aquatic invertebrates, was bioenergetically determined. Energy-budget estimations showed negative net growth efficiency $\left(K_{2}\right)$ in the largest adults at temperatures above $20^{\circ} \mathrm{C}$. The relationship between $K_{2}$ and temperature showed a dome-shaped pattern, $K_{2}$ values for larger amphipods being maximal at lower temperatures. Seasonal migrations of adult $H$. azteca from shallow littoral to deeper cold habitats, observed in lakes during the warmest periods, appear to be temperature-induced and bioenergetically advantageous, despite probable increases in predation risk experienced in spatially simple deep-water habitats.
\end{abstract}

\begin{abstract}
Résumé : Les taux de croissance individuels d'amphipodes d'eau douce Hyalella azteca (Saussure) ont été mesurés dans la zone littorale de deux petits lacs oligotrophes d'Ontario et dans des installations expérimentales offrant un gradient naturel de température $\left(10,15,20\right.$ et $\left.23^{\circ} \mathrm{C}\right)$. Les observations en nature ont démontré que le déclenchement et la cessation des stades inactifs de reproduction de l'amphipode requièrent une température de $20^{\circ} \mathrm{C}$.La croissance des petits amphipodes est davantage affectée par la température que celle des gros. Les variables de la croissance sont en relation linéaire avec les températures d'élevage et les régressions peuvent servir de modèle simple dans les calculs bioénergétiques chez les crustacés. Une corrélation négative a été trouvée entre la température de l'eau et les tailles maximales atteintes par les amphipodes. Les adultes les plus gros étaient absents des populations étudiées durant les périodes de température élevée l'été et ce phénomène, déjà observé chez d'autres invertébrés aquatiques, est sous contrôle bioénergétique. L'estimation des budgets énergétiques a mis en relief une efficacité de croissance nette négative $\left(K_{2}\right)$ chez les plus gros adultes aux températures supérieures à $20^{\circ} \mathrm{C}$. La relation entre $K_{2}$ et la température suit une courbe en dome et le $K_{2}$ des plus gros amphipodes est maximal aux températures plus basses. Les migrations saisonnières effectuées par les adultes d'H. azteca, des eaux peu profondes aux habitats plus profonds et plus froids, migrations observées dans les lacs pendant les périodes les plus chaudes, semblent déclenchées par la température et comporter des avantages bioénergétiques en dépit de l'augmentation probable des risques de prédation dans les habitats d'eau profonde de configuration simple.

[Traduit par la Rédaction]
\end{abstract}

\section{Introduction}

Water temperature is one of the most important factors influencing the life-history characteristics and distribution of aquatic ectothermic animals. Temperature affects rates of metabolism, growth, and development in aquatic invertebrates (Sweeney 1984; Winberg 1987). It is a common observation in field and laboratory studies of ectothermic animals that increasing temperature results in reduced size (for a review see Atkinson 1994). Ray (1960) was among the first to

Received May 21, 1997. Accepted January 30, 1998.

V.E. Panov. Zoological Institute, Russian Academy of Sciences, 199034 St. Petersburg, Russia.

D.J. McQueen ${ }^{1}$. Department of Biology, York University, 4700 Keele Street, Toronto, ON M3J 1P3, Canada.

1 Author to whom all correspondence should be addressed. note that the temperature-dependent relationship between anabolism and catabolism might explain observed the negative relationship between temperature and animal size. Von Bertalanffy (1960) concluded from theoretical considerations that smaller size at high temperature is a result of higher temperature coefficients for catabolism than for anabolism. This suggestion was supported later by analysis using von Bertalanffy's growth equation, expressed as a budget (Sukhanov 1979; Perrin 1995; but see Atkinson 1994). The effects of food supply and temperature on age and size at maturity in ectotherms, and their theoretical implications, were recently intensively debated by Berrigan and Charnov (1994), Ernsting (1995), Perrin (1995), Sevenster (1995), and Atkinson and Sibly (1996); however the problem of sizetemperature responses in ectotherms is still unresolved and requires further study.

Because there are strong relationships between population dynamics and temperature-dependent physiological processes at the individual level, simple ecophysiological models 
relating abiotic factors and physiological functions (feeding, respiration, reproduction, and aging) will greatly enhance attempts to explain population dynamics in terms of physiology (Metz and Diekmann 1986; Kooijman et al. 1989; Halat and Lehman 1996). We believe that the development of such models, based on empirical data, will contribute to the verification of existing models addressing the evolution of age and size at maturity, as well as life-history theory (Stearns and Koella 1986; Kozlowski 1992; Stearns 1989, 1992).

Expected climate change due to global warming will influence the life-history characteristics and biogeography of aquatic invertebrates, but the magnitude of the effect is uncertain, owing to significant information gaps in such areas as the physiological basis of life-history traits and development dynamics (Sweeney et al. 1991). In this respect, understanding and modelling temperature effects on the life-history characteristics of aquatic animals can contribute significantly to ongoing attempts to project climate-change effects at the population and community level (Chen and Folt 1996; De Stasio et al. 1996; Hairston 1996; Hogg and Williams, 1996; McDonald et al. 1996).

The first objective of the work reported here was to quantify the relationship between temperature and individual growth rate in different size classes of a freshwater amphipod, Hyalella azteca (Saussure), and to offer physiologicalbioenergetic explanations for the negative relationship between temperature and size in crustaceans. It is known that adults in natural populations of $H$. azteca undergo seasonal size cycles (Cooper 1965; Strong 1972), the smallest animals appearing in the summer. An increase in water temperature in artificial channels resulted in significant decreases in the body sizes of adult $H$. azteca (Lozano and Kitchell 1978; Hogg and Williams 1996). Also, the laboratory observations of de March (1978) suggested that development time and final body sizes in $H$. azteca that were given adequate food were inversely related to temperature. Physiological explanations for these temperature-dependent size responses in H. azteca are not found in the literature.

Our second objective was to investigate some implications of the size-temperature response for the life history and population dynamics of $H$. azteca. Because $H$. azteca is a common and abundant species in shallow habitats in many lakes, ponds, and streams in North America (Pennak 1953; Bousfield 1958), accurate growth measurements are essential for evaluating its role in matter and energy transfer in the communities. Despite the fact that growth-temperature relationships are important for estimating secondary production, there are no detailed data for different size classes of $H$. azteca. Also, laboratory populations of $H$. azteca are commonly used in toxicity testing (Borgmann and Munavar 1989). Therefore, base-line information pertaining to temperature effects may be essential for experiment planning and interpretation.

\section{Methods}

Populations of $H$. azteca were sampled in the littoral zone of Mouse and Ranger lakes (south-central Ontario, Canada). Quantitative samples of littoral macrobenthos were taken bimonthly from May through September 1994 along one transect in Mouse Lake $\left(78^{\circ} 50^{\prime} 37^{\prime \prime} \mathrm{W}, 45^{\circ} 11^{\prime} 08^{\prime \prime} \mathrm{N}\right)$ and two transects in Ranger Lake (transect A: $78^{\circ} 51^{\prime} 00^{\prime \prime} \mathrm{W}, 45^{\circ} 09^{\prime} 10^{\prime \prime} \mathrm{N}$; transect B: $78^{\circ} 50^{\prime} 55^{\prime \prime} \mathrm{W}$, $\left.45^{\circ} 09^{\prime} 05^{\prime \prime} \mathrm{N}\right)$ at standard depths $0.4,0.6,0.8$, and $1.0 \mathrm{~m}$ with an original $40 \mathrm{~cm}$ diameter core sampler described earlier (Panov and Pavlov 1986), and at depths of $1.5,2$, and $3.5 \mathrm{~m}$ with a Petit-Ponar grab. During sampling of hard gravel and cobble substrates, a $4 \mathrm{~m}$ long iron pole was fixed to the grab. Samples taken with the core sampler were replicated twice (sampling area $0.125 \mathrm{~m}^{2}$ ) and those with the grab sampler 5-8 times (sampling area $0.025 \mathrm{~m}^{2}$ ). This ensured that the standard error of replicate samples averaged $20 \%$ of the mean density of the main groups of invertebrates (Downing 1979). The field samples were preserved in $4 \%$ formalin and transported in plastic bags to the laboratory, where macroinvertebrates were sorted and counted. Collected amphipods were mounted in a clearing medium and the length of their heads was measured using a computer-based video overlay system (ZCOUNT). Head length was measured along the dorsal margin of the head.

Separate collections were made bimonthly (during summer) to determine length-mass relations and numbers of eggs. Head length was measured under a dissecting microscope, using an ocular micrometer, and the amphipods were then weighed alive to the nearest $0.001 \mathrm{mg}$ on a CAHN 29 automatic electrobalance. They were then dried to constant mass at $60^{\circ} \mathrm{C}$ and weighed again. Linear regressions were determined after logarithmic transformation of length and mass.

Growth rates of $H$. azteca in natural populations were obtained from analyses of the size-frequency distributions of amphipods from the shallow littoral zone (depths $<1 \mathrm{~m}$ ) throughout the season. Amphipods were sorted into 26 size classes with head lengths ranging from 0.16 to $0.66 \mathrm{~mm}$, i.e., $0.16-0.18,>0.18-0.20 \mathrm{~mm}$, etc.

Because H. azteca were scarce or absent in the cooler water deeper than $1 \mathrm{~m}$, separate growth experiments were conducted over the natural temperature gradient $\left(10,15,20\right.$, and $\left.23^{\circ} \mathrm{C}\right)$. For the growth experiments, amphipods collected in the littoral zone of Ranger Lake were measured and transferred to $0.5-\mathrm{L}$ plastic bottles (from 2 to 5 specimens per bottle depending on amphipod size; 2 or 3 for adults and 4 or 5 for juveniles). Each bottle was 3/4 filled with lake water, closed, and put in a minnow trap. Sets of experimental bottles in minnow traps (up to 10 bottles per trap) were placed on the lake bottom at different depths to expose amphipods to temperatures of 10,15 , 20 , and $23^{\circ} \mathrm{C}$. Temperature at the lake bottom was monitored every 3 days and, when necessary, minnow traps with experimental bottles were moved to the depth with the proper experimental temperature. Time of exposure varied from 12 to 16 days for temperatures of 20 and $23^{\circ} \mathrm{C}$ and from 20 to 30 days at 10 and $15^{\circ} \mathrm{C}$, to allow measurable changes in amphipod head lengths to be obtained. It should be noted that temperatures in the shallow littoral zone fluctuated more than those measured in deeper water. To reduce the potential for confounding of growth-rate measurements because of the effects of different temperature means and temperature fluctuations, we restricted our analysis of experimental growth data to July and August, when temperature fluctuations in the shallow littoral zone were minimal (Fig. 1).

Periphyton and macrophyte debris collected in the littoral zone of Ranger Lake were used as food and substrate for amphipods in amounts sufficient to provide a high level of food availability at all experimental temperatures. The dry mass of food material (100 $300 \mathrm{mg}$ ) was at least two orders of magnitude greater than the dry mass of amphipods reared in the experimental bottles. Experimental bottles were darkened to prevent photosynthesis (to keep food quality constant in all treatments), and the minnow traps were covered with aluminum foil to prevent heating of the bottles by solar radiation. Every 5 days, water and food in the experimental bottles was changed. We used large bottles $(0.5 \mathrm{~L})$ that were $3 / 4$ filled with lake water, leaving at least $100 \mathrm{~mL}$ headspace filled with air (so that atmospheric oxygen was available to replace dissolved oxygen lost through depletion). At the end of experiment the amphipods were measured under a dissecting microscope and their wet and dry masses were estimated as above. Temperatures in the littoral zone of 
Fig. 1. Temperature at different depths in the littoral zone of Ranger Lake (a) and Mouse Lake (b) in 1994.

\section{(a)}

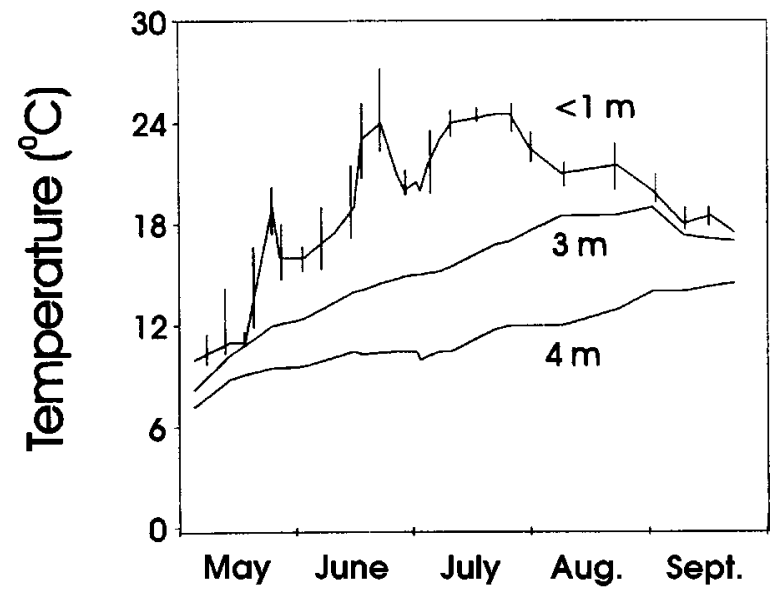

(b)

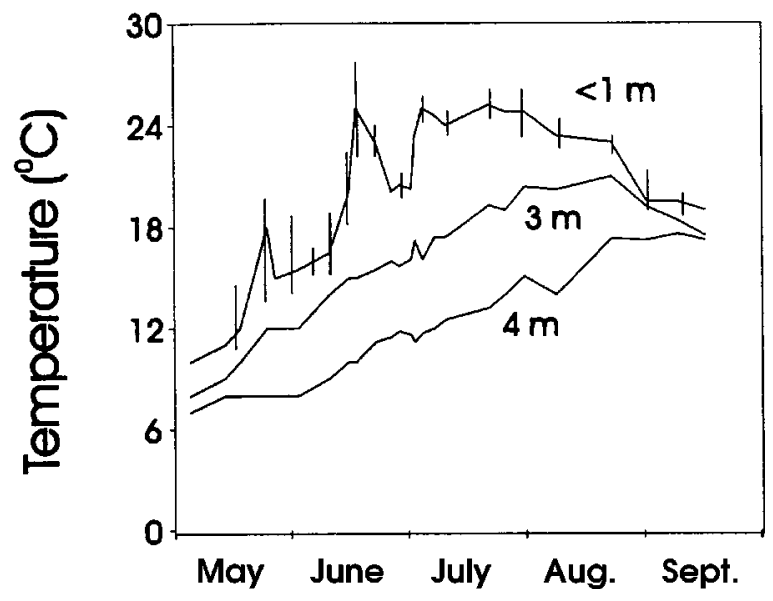

Ranger and Mouse lakes were monitored during the season, using both automatic recorders and maximum-minimum thermometers. The temperature regimes in the two lakes were similar (Fig. 1).

Head lengths of amphipods, $L_{\mathrm{h}}$, were converted to dry body mass, $W$, from the $\log$ - $\log$ regression $\log (W)=a+b \log \left(L_{\mathrm{h}}\right)$, where $b$ is the exponent coefficient. Specific growth rates of $H$. azteca $\left(G_{\mathrm{s}}\right)$, were estimated from the expression $G_{\mathrm{s}}=\ln \left(W_{2} / W_{1}\right) /\left(t_{2}-t_{1}\right)$, where $W_{1}$ and $W_{2}$ are amphipod dry body masses at times $t_{1}$ and $t_{2}$, and $t_{2}-t_{1}$ is the time elapsed between sampling dates or the time of exposure (in days). The $G_{\mathrm{s}}$ value was related to mean mass, which was calculated from the expression $W^{\prime}=\left(W_{2}-W_{1}\right) / \ln \left(W_{2} / W_{1}\right)$.

The growth of amphipods was described by von Bertalanffy's equation $W_{\mathrm{t}}=\mathrm{W}_{\infty}\left(1-\mathrm{e}^{-k t}\right)^{b}$, where $W_{\mathrm{t}}$ is body mass at time $t, \mathrm{~W}_{\infty}$ is the theoretical maximum (asymptotic) mass, and $k$ is the growth coefficient. Parameters $W_{\infty}$ and $k$ were estimated from the linear regression of specific growth rate on mean body mass, $G_{\mathrm{s}}=-k^{\prime}+N \times$ $W^{\prime-1 / b}$, where $b$ is the exponent (slope) calculated by linear regression between head length and dry body mass and $k^{\prime}$ and $N$ are constants: $W=\left(N / k^{\prime}\right)^{b}$ and $k=k^{\prime} / b$.

The net growth efficiency coefficient $\left(K_{2}\right.$; based on somatic growth measurements of non-reproducing animals) was calculated from $P_{\mathrm{s}} /\left(P_{\mathrm{s}}+R\right)$, where $P_{\mathrm{s}}$ is the somatic growth rate and $R$ is the respiration rate. Respiration rates (in milligrams of oxygen per hour per
Fig. 2. Relationship of wet mass $(\bigcirc)$ and dry mass $(\square)$ to head length for Hyalella azteca.

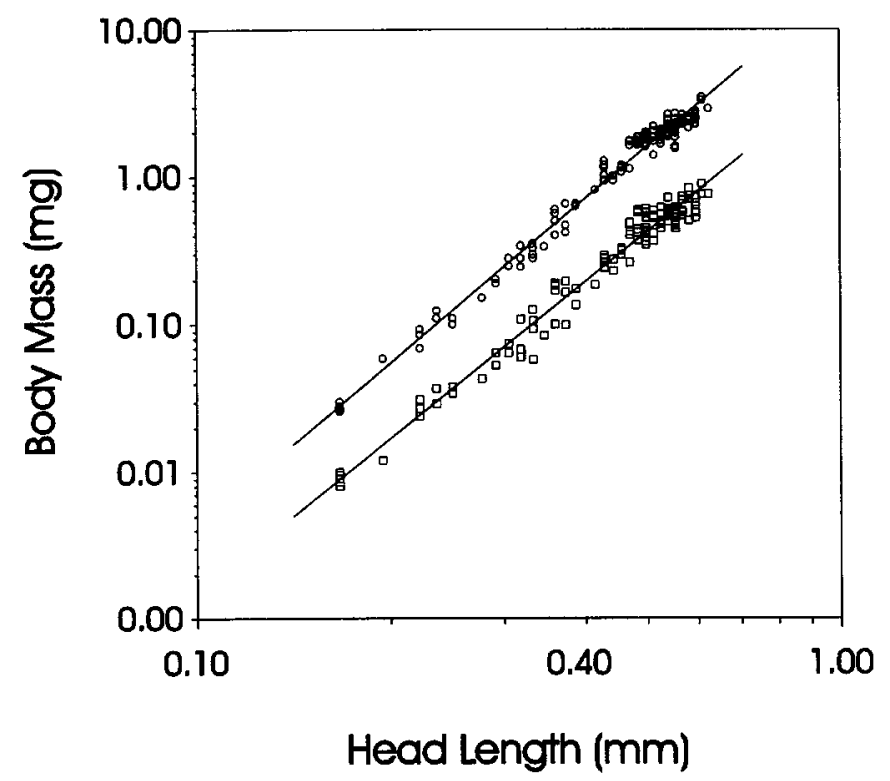

individual) and $Q_{10}$ values for metabolism were calculated from Mathias (1971): $R=0.00141$ dry mass ${ }^{0.668}$ at $15^{\circ} \mathrm{C}$ and $Q_{10}=2.8$ in the temperature interval $10-24^{\circ} \mathrm{C}$. Respiration in milligrams of oxygen per hour per individual was converted to calories per hour per individual, using the oxycaloric equivalent $\left(3.38 \mathrm{cal} / \mathrm{mg} \mathrm{O}_{2}\right.$; Elliott and Davison 1975). Calorific values for H. azteca (4.086 cal/mg dry mass for juveniles and $3.850 \mathrm{cal} / \mathrm{mg}$ dry mass for adults) are from Mathias (1971).

\section{Results}

\section{Length-mass regressions}

The relationship between individual wet mass in milligrams (WW) and head length in millimetres $\left(L_{\mathrm{h}}\right)$ for $H$. azteca (Fig. 2) is described by the regression

$$
\begin{aligned}
& \log (\mathrm{WW})=(1.302 \pm 0.017) \\
& +(3.662 \pm 0.044) \log \left(L_{\mathrm{h}}\right)
\end{aligned}
$$

(df $=118, P<0.001)$, and the relationship between individual dry mass in milligrams (DW) and head length in millimetres is

$$
\begin{aligned}
& \log (\mathrm{DW})=(0.677 \pm 0.021) \\
& +(3.513 \pm 0.054) \log \left(L_{\mathrm{h}}\right)
\end{aligned}
$$

$(\mathrm{df}=118, P<0.001)$.

The fecundity of female amphipods of the same size did not differ between lakes or between summer months, which may reflect stable food conditions for this grazing amphipod in both studied lakes during most of the time of our study, and the relationship between the number of eggs $(E)$ and head length in millimetres $\left(L_{\mathrm{h}}\right)$ in $H$. azteca is described by the regression

[3] $\log (E)=(1.558 \pm 0.062)+(2.163 \pm 0.196) \log \left(L_{\mathrm{h}}\right)$

(df $=86, P<0.001)$.

\section{Growth in the lakes}

Reproduction of $H$. azteca in the two lakes started in late May, when the temperature reached $20^{\circ} \mathrm{C}$ (ovigerous females 
Fig. 3. Size-frequency distributions (individuals $/ \mathrm{m}^{2}$ ) of Hyalella azteca from transect A in Ranger Lake. Open bars indicate ovigerous females.
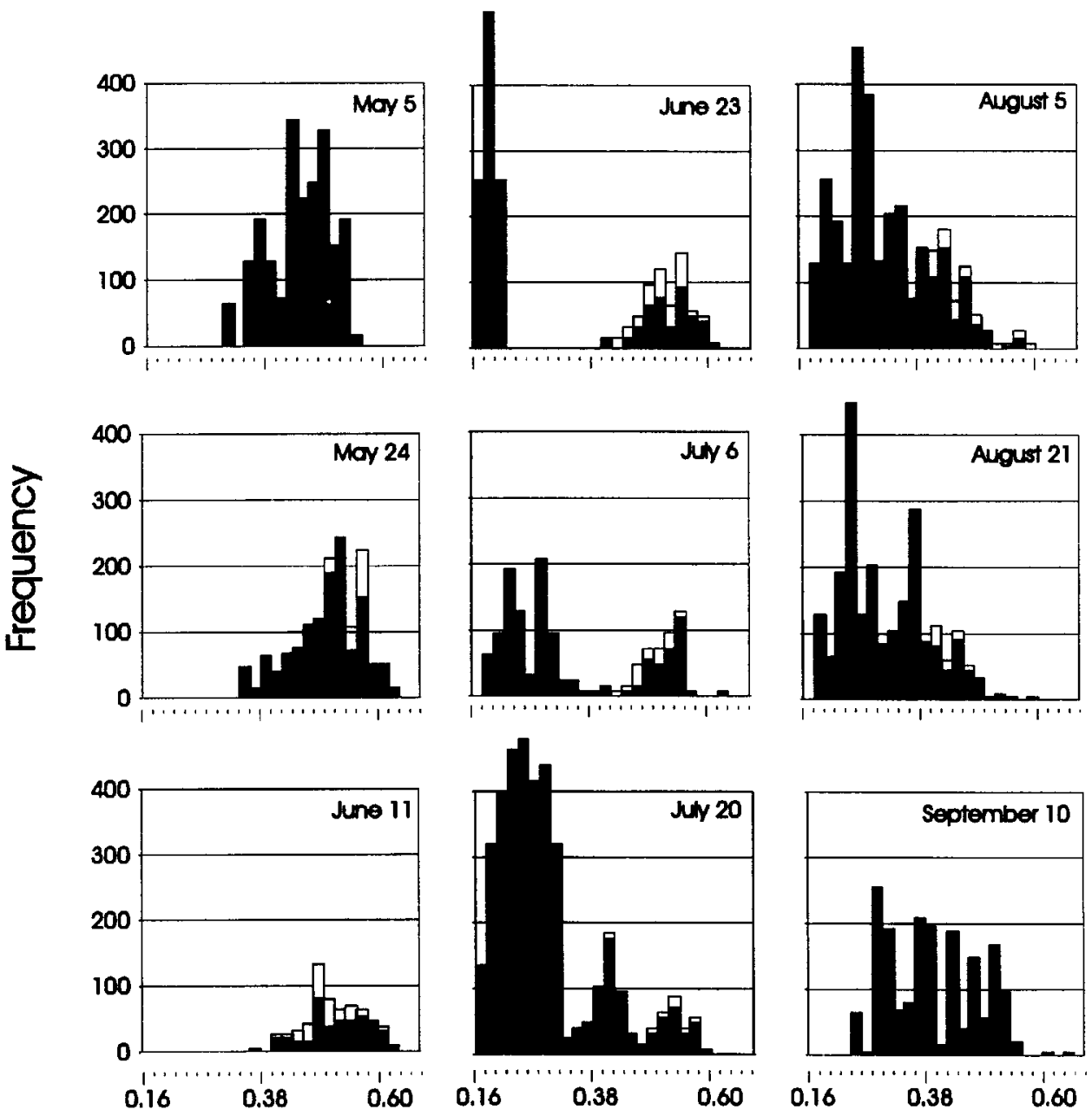

Head Length $(\mathrm{mm})$

Fig. 4. Mean head lengths with respect to sampling date (time of year) for Hyallela azteca in the littoral zone in Mouse Lake ( $\mathbf{\Delta})$, transect A in Ranger Lake ( $\square$ ), and transect B in Ranger Lake (O). Standard error bars are smaller than the line markers and are not shown.

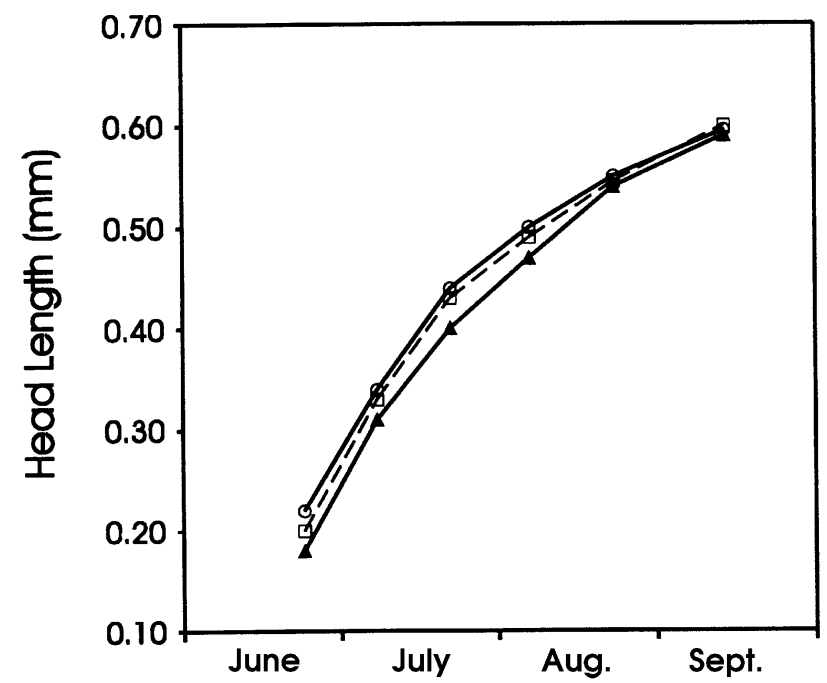

were first recorded in populations at this time; Fig. 3). Juveniles of the first generation appeared in the littoral zone of both lakes in late June, and in about 40 days, females of this generation became mature. As a result, the second peak of juveniles appeared in August. Size-frequency distributions for $H$. azteca in May also had clear two-peak patterns (Fig. 3). Mean sizes of ovigerous females gradually decreased during the summer, from $0.5 \mathrm{~mm}$ (head length) to $0.4 \mathrm{~mm}$. Amphipod reproduction ceased in early September, when the temperature in the shallow littoral zone dropped below $20^{\circ} \mathrm{C}$.

The largest amphipods (with head lengths $>0.64 \mathrm{~mm}$ ) were found only during May and September, when the littoral-zone temperature was below $20^{\circ} \mathrm{C}$. During the summer, maximum sizes never exceeded $0.62-0.64 \mathrm{~mm}$ (Fig. 3). From the H. azteca size-frequency distributions it was possible to obtain reliable growth data only for individuals of the first generation. For this cohort, all study sites yielded similar growth patterns, and head lengths reached $0.59-0.61 \mathrm{~mm}$ in September (Fig. 4). Calculated parameters for regression-related specific growth rates with respect to mean dry mass in the littoral areas of Ranger and Mouse lakes, as well as parameters for von Bertalanffy's growth equation, are shown in Table 1. 
Table 1. Parameters of equations relating specific growth rates to mean body mass and von Bertalanffy's growth equations for Hyalella azteca at different temperatures.

\begin{tabular}{ccccc}
\hline Temp. $\left({ }^{\circ} \mathrm{C}\right)$ & $k^{\prime}$ & $N$ & $W_{\infty}$ & $k$ \\
\hline 10 & $0.0060 \pm 0.0025$ & $0.0092 \pm 0.0015$ & $4.68 \pm 0.55$ & $0.0017 \pm 0.0003$ \\
15 & $0.0174 \pm 0.0033$ & $0.0233 \pm 0.0034$ & $2.52 \pm 0.30$ & $0.0055 \pm 0.0006$ \\
20 & $0.0484 \pm 0.0096$ & $0.0581 \pm 0.0060$ & $1.90 \pm 0.36$ & $0.0138 \pm 0.0015$ \\
23 & $0.0856 \pm 0.0128$ & $0.0872 \pm 0.0065$ & $1.07 \pm 0.17$ & $0.0244 \pm 0.0021$ \\
$23 *$ & $0.0835 \pm 0.0062$ & $0.0868 \pm 0.0033$ & $1.15 \pm 0.23$ & $0.0238 \pm 0.0024$ \\
\hline
\end{tabular}

Note: Values are given as the mean $\pm \mathrm{SE}$.

*Natural populations in Ranger and Mouse lakes.

Fig. 5. Mass-specific somatic growth rates for Hyalella azteca at different temperatures plotted against individual mean dry mass. (a) Experimental data obtained at $23^{\circ} \mathrm{C}(\bullet)$, field transect data from Mouse Lake ( $\boldsymbol{\Delta}$; mean $\pm 1 \mathrm{SE})$, and field transect data from transect A in Ranger Lake ( $\square$; mean $\pm 1 \mathrm{SE})$ and transect B in Ranger Lake $(\bigcirc$; mean $\pm 1 \mathrm{SE})$. (b) Experimental data obtained at $10^{\circ} \mathrm{C}(\boldsymbol{\Delta}), 15^{\circ} \mathrm{C}$ $(\square)$, and $20^{\circ} \mathrm{C}(\boldsymbol{\square})$. The lines were fit by least squares regression (for parameters see Table 1) and have different slopes (homogeneity of slope (GLM), $p<0.001)$.

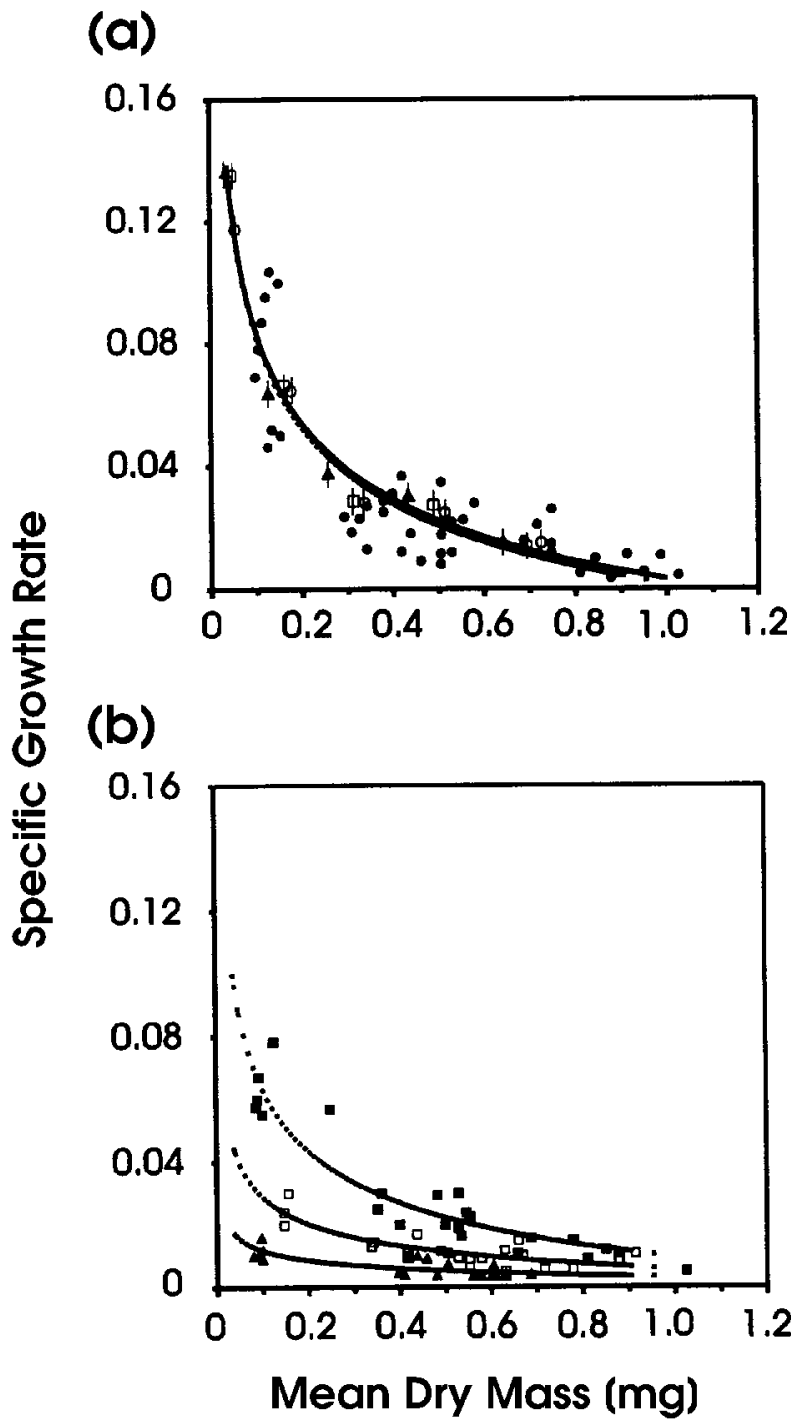

Fig. 6. Asymptotic dry mass $\left(W_{\infty}\right)$ of Hyalella azteca at different temperatures $(\mathbf{\Delta})$; experimental data are from de March (1978) for males ( $\square$ ) and females ( $\square$ ) and field observations of Losano and Kitchell (1978) (O). Vertical lines indicate 95\% confidence limits.

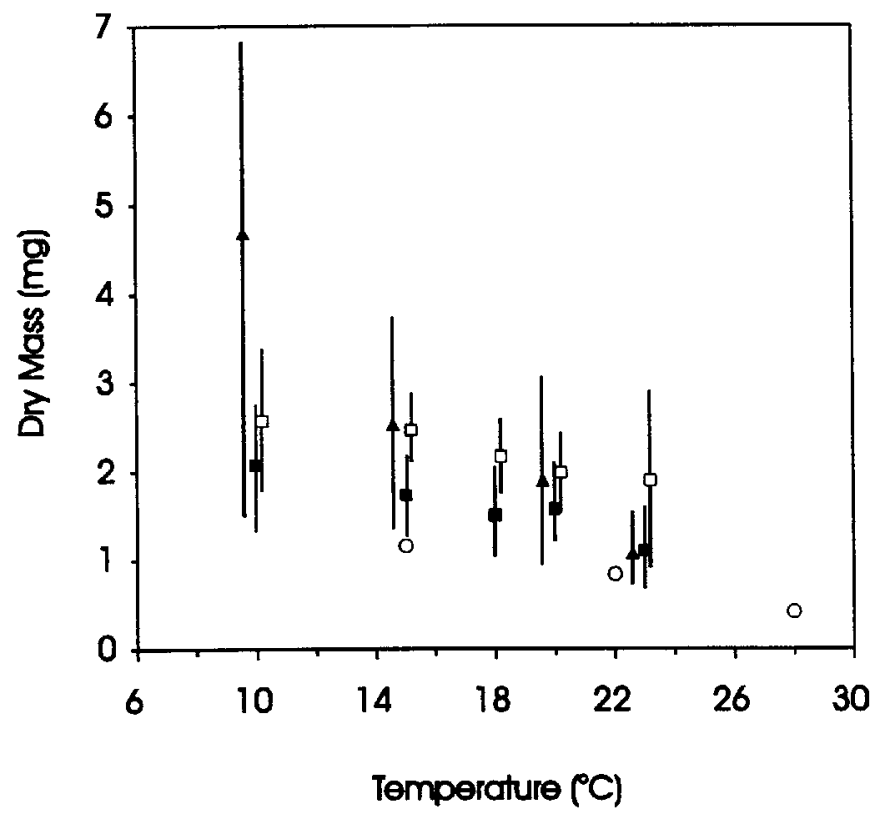

\section{Growth experiments}

Specific somatic growth rates for $H$. azteca grown in the shallow littoral zone (depth $0.4-1.0 \mathrm{~m}$, mean temperature $23^{\circ} \mathrm{C}$ ) were very close to the growth rates estimated for the first generation monitored in Ranger and Mouse lakes (Fig. 5). Parameters of the growth equations were also similar (Table 1). The coincidence of these rates suggests that growth conditions (food quantity and quality and adequate dissolved oxygen levels) in the experimental bottles were natural. Survivorship tended to decrease with temperature, being 91, 86, 69, and $70 \%$ at $10,15,20$, and $23^{\circ} \mathrm{C}$, respectively.

Growth rates decreased with increasing size but increased with temperature (Fig. 5). Juveniles showed the greatest increase in growth rates with temperature. With increasing size, growth rates of amphipods were gradually less dependent on temperature. Consequently, the estimated values of $W_{\infty}$ in the growth equations decreased with temperature (Table 1, Fig. 6). The growth coefficient $k$ and parameters $k^{\prime}$ and $N$ showed a positive relationship with temperature 
Fig. 7. Net growth efficiency $\left(K_{2}\right)$ for six size groups of Hyalella azteca at different temperatures. Symbols indicate empirical estimations ( $\boldsymbol{\Lambda}$, juveniles; $\boldsymbol{\bullet}$, adults) and solid lines indicate model estimations. Numbers above the lines denote amphipod body dry mass (mg) in the size group, and the four largest numbers correspond to asymptotic dry mass in von Bertalanffy's growth equation.

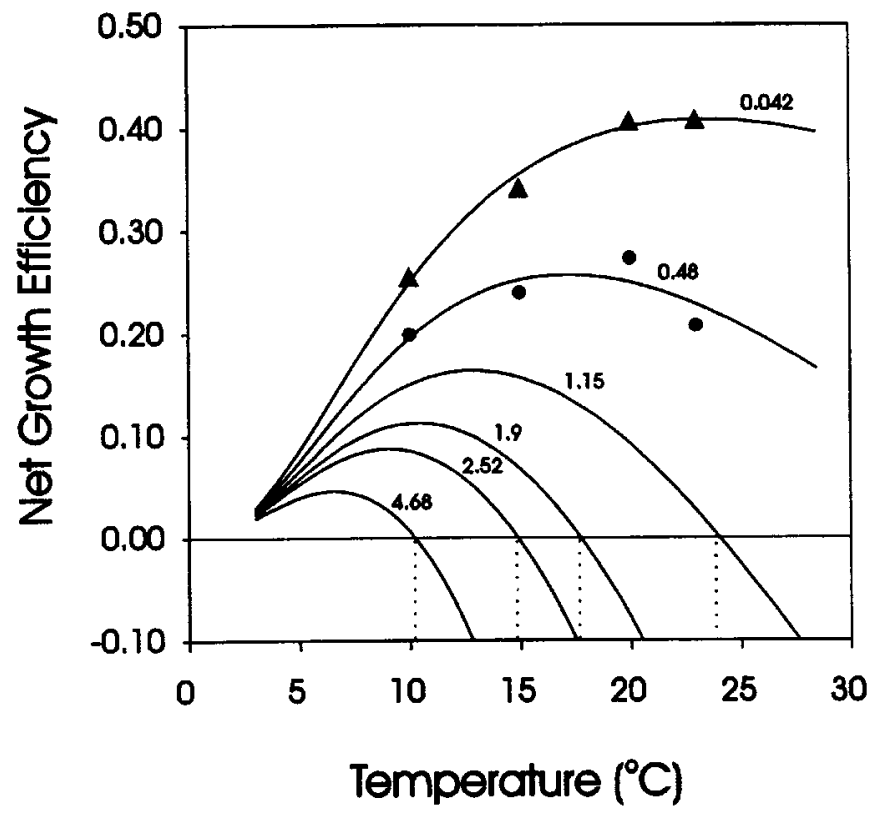

(Table 1). The relationships between the parameters $k^{\prime}, N$, and temperature $\left(T,{ }^{\circ} \mathrm{C}\right)$ are described by the regressions

$$
\log \left(k^{\prime}\right)=(-5.420 \pm 0.034)+(3.175 \pm 0.125) \log (T)
$$

and

$$
\text { [5] } \log (N)=(-4.754 \pm 0.025)+(2.705 \pm 0.090) \log (T)
$$

$K_{2}$ values calculated using regressions 4 and 5 for growthrate estimations and temperature showed a dome-shaped pattern (Fig. 7). $K_{2}$ values calculated from empirical growth data fit the model estimations well. Model estimations of $K_{2}$ for animals with dry mass $1.15,1.9,2.52$, and $4.68 \mathrm{mg}$ (asymptotic mass at 23, 20, 15, and $10^{\circ} \mathrm{C}$, respectively; Table 1) approached zero and became negative at 23.5, 17.5, 14.5 , and $10.5^{\circ} \mathrm{C} . K_{2}$ values for larger animals were maximized at lower temperatures (Fig. 7).

\section{Discussion}

Our data pertaining to the temperature at which reproduction of H. azteca occurs in Ranger and Mouse lakes correspond to the results of de March (1977), who concluded that $20^{\circ} \mathrm{C}$ is an important temperature for both the induction and termination of reproductive resting stages in this amphipod. Field observations from other North American lakes also show that a temperature of $20^{\circ} \mathrm{C}$ controls the reproductive resting stage in H. azteca (Embody 1911; Geisler 1944; Cooper 1965).

A negative relationship between maximum size and temperature in $H$. azteca has been shown in the laboratory (de March 1978) and the field (Lozano and Kitchell 1978). The maximum sizes of $H$. azteca at different temperatures are similar to those calculated $\left(W_{\infty}\right)$ in the present study (Fig. 6).
Fig. 8. Net growth efficiency $\left(K_{2}\right)$ for seven size groups of Asellus aquaticus at different temperatures. Symbols indicate empirical estimations ( $\boldsymbol{\Delta}$, small adults; $\boldsymbol{\bullet}$, large adults) and solid lines indicate model estimations. Numbers above the lines denote isopod body dry mass (mg) in the size group, and the five largest numbers correspond to asymptotic dry mass in von Bertalanffy's growth equation.

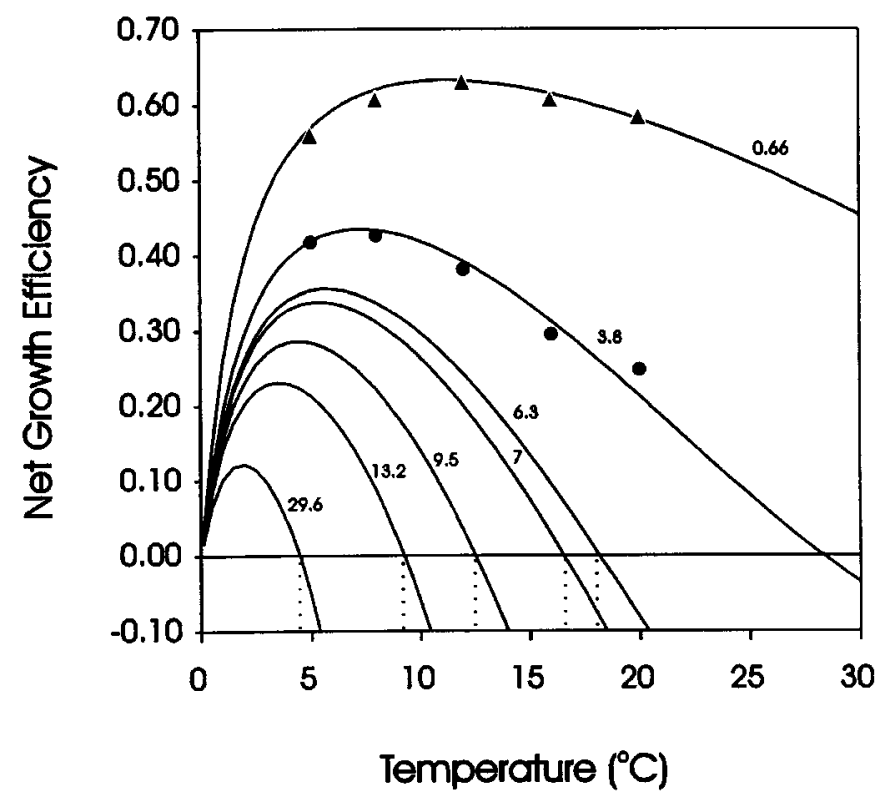

The largest size for this amphipod (1.1 mm head length, $6.6 \mathrm{mg}$ dry mass) is known from old, cold-water laboratory populations (de March 1978). This large size is near the asymptotic size of H.azteca, calculated from our experimental data at $10^{\circ} \mathrm{C}$ (head length about $1.0 \mathrm{~mm}$ ).

The absence of large adults in summer populations (noted for H. azteca by Cooper 1965; Strong 1972; this study) was also shown for the freshwater isopod Asellus aquaticus L. (Thompson 1986; Zhemaeva 1987; Panov 1988a), and temperature is likely to be the main factor limiting maximum size. Rearing experiments on laboratory populations of this isopod also showed a negative relationship between $W_{\infty}$ and temperature (Panov 1988a; Mladenova 1991). For A. aquaticus, calculated $W_{\infty}$ values were close to the maximum sizes observed at corresponding temperatures in both the experiments and in nature.

For H. azteca, the relationships between the growth parameters and temperature for $A$. aquaticus can be described by the regressions (growth data from Panov 1988a)

$$
\log \left(k^{\prime}\right)=(-3.289 \pm 0.039)+(1.547 \pm 0.081) \log (T)
$$

and

$$
\log (N)=(-2.242 \pm 0.019)+(1.135 \pm 0.040) \log (T)
$$

Using this model and respiration data for A. aquaticus $(R(\mathrm{mg}$ $0_{2} / \mathrm{h}$ per individual $)=0.00201 \mathrm{mg}$ dry mass ${ }^{0.765}$ at $20^{\circ} \mathrm{C}$ (Panov 1986, 1995); $Q_{10}=2.25$ (Mladenova 1993)), we calculated $K_{2}$ for small (0.66 mg dry mass) and medium-sized (3.8 mg dry mass) adults and for large isopods of 6.3, 7, 9.5, 13.2 , and $29.6 \mathrm{mg}$ dry mass, which are equal in size to the asymptotic body masses at rearing temperatures of 20, 16, 12, 8 , and $5^{\circ} \mathrm{C}$, respectively (Panov 1988a). The resulting (Fig. 8) 
relationship between $K_{2}$ and temperature for different size groups of A. aquaticus also has a dome-shaped pattern, and model estimations of $K_{2}$ for large isopods with asymptotic body masses approach zero at temperatures associated with rearing.

As we have shown for $H$. azteca and earlier for A. aquaticus (Panov 1988a), temperature affects growth much more in small individuals. This means that the $Q_{10}$ value for growth is dependent on body size. Maximum $K_{2}$ corresponds to the optimal temperature at which $Q_{10}$ values for growth and metabolism are equal (Winberg 1987). Winberg (1983) has shown that for acclimated ectothermic animals, $Q_{10}$ estimates for metabolism vary little with temperature and are generally within the range 2.0-2.5. According to Winberg (1983), a mean $Q_{10}$ value of 2.25 can be applied to most ectotherms within the range of tolerable temperatures (i.e., $Q_{10}$ for metabolism, calculated from Mathias (1971), is 2.8 for both juvenile and adult $H$. azteca at temperatures ranging from 10 to $22^{\circ} \mathrm{C}$, and $Q_{10}$ for metabolism is 2.25 for different size groups of $A$. aquaticus at temperatures ranging from 5 to $22^{\circ} \mathrm{C}$ (see Mladenova 1993)). Therefore, the maximum $K_{2}$ value in large individuals is found at lower temperatures, and approaches zero at some higher temperatures. This corresponds well to the rearing temperatures for animals that achieve asymptotic sizes (Figs. 7 and 8). At some higher temperatures, $K_{2}$ values for large individuals may be negative (in the case of negative growth).

Estimates of food consumption rates $(C)$ and respiration rates $(R)$ made by Strong and Daborn (1980) for the marine isopod Idotea baltica (Pallas) represent one of the first attempts to offer a physiological explanation for the negative size-temperature relationship in poikilotherms. They showed that the $C: R$ ratio allows the greatest scope for growth at the highest temperatures for small isopods and the least scope for large isopods. Strong and Daborn (1980) concluded that the differential effects of temperature on ingestion and metabolism explain differences in maximum size in crustaceans, and that this may have a wider significance for population dynamics in poikilotherms (temperature-dependent size-selective mortality). For example, Strong and Daborn (1980) suggested that environmental temperatures in midsummer may be so high in some habitats that the largest male $I$. baltica are unable to ingest enough food to meet respiration costs and rapidly die.

Using data from these authors (Strong and Daborn 1979, 1980 ), we calculated $K_{2}$ (a more reliable indicator of metabolism than $C: R)$. As in H. azteca and A. aquaticus, the relationship between $K_{2}$ and temperature in I. baltica was domeshaped, with maximum $K_{2}$ at $14^{\circ} \mathrm{C}$ for small isopods and $9^{\circ} \mathrm{C}$ for large individuals. These data suggest that the relationship between $K_{2}$ and temperature in crustaceans is size-dependent, with optimal temperatures (temperatures corresponding to maximum $K_{2}$ ) being inversely related to size (Fig. 9). This is likely to be a general rule not only for crustaceans but for other groups of poikilotherms as well. For instance, the rearing temperatures producing the largest larvae of certain instars of Chaoborus flavicans (Insecta: Diptera) decreased with increasing body size (Hanazato 1989).

At high summer temperatures, the metabolic rates of the largest animals exceed assimilated energy levels, and this leads to the disappearance of larger individuals from summer
Fig. 9. Relationship between optimal temperature for growth and dry mass in Hyalella azteca (ם), Asellus aquaticus $(\square)$, and Idotea baltica $(-)$. Data for I. baltica are not included in the regression calculations.

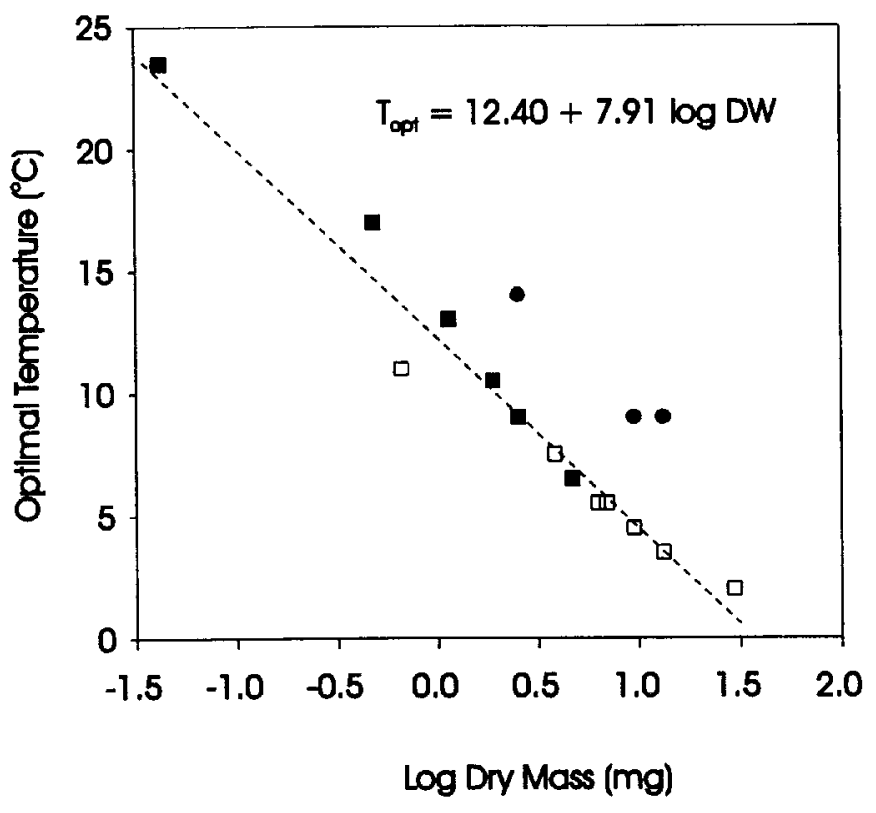

populations and the exclusion of larger individuals from warmer habitats. It has been shown by Hanazato (1991) that the survival rate of Daphnia ambigua reared at $30^{\circ} \mathrm{C}$ gradually declined with size from $100 \%$ in two early instars to zero in the last instar, and chemicals released by a predator (Chaoborus sp.) caused the drastic increase in size-selective mortality (highest in large animals) at high temperatures, probably due to additional energy costs for the development of antipredator morphological structures. In view of these results, the observed summer decline in body size and population density of $D$. ambigua in some lakes can be attributed not only to size-selective predation by fish (Threlkeld 1979) but also to the reduction in temperature-induced size-selective mortality and growth rate at high midsummer temperatures, enhanced by the indirect effects of fish presence (additional energy costs of antipredator behavior and cyclomorphosis).

The latitudinal differences in body size (Bergmann's Rule) observed, for instance, by Steele and Steele (1975) in marine species of Gammarus, are likely bioenergetically determined. A detailed theoretical analysis of Bergmann's Rule (considered to be a negative relationship between latitudinal temperature and body size) in poikilotherms has been offered by Sukhanov (1979), who based his analysis on von Bertalanffy's growth model and analyzed the equations relating assimilation and respiration rates with respect to temperature and food conditions. His analysis supported the existence of an inverse relationship between asymptotic body size (or age) and temperature, and he also suggested that the temperature at which the growth rate is maximized shifts higher with increasing food levels. This relationship was also found in young salmonids (Brett et al. 1969) and the freshwater amphipod Gammarus lacustris Sars, which showed a fourfold increase in asymptotic mass at the same temperature but different food levels (Panov 1988b). Also the isopod A. aquati- 
cus grew much larger in a sewage ditch than in the more oligotrophic Neva Bay littoral zone (Panov 1988a). A correlation between food supply and adult size has also been shown for other invertebrates (Sweeney and Vannote 1986; Sweeney et al. 1986; Ernsting et al. 1993; Kooijman 1993).

These confounding relationships between temperature and food and metabolic processes can have a profound influence on the interpretation of both field observations and the results of laboratory growth experiments (Sweeney et al. 1986). Data from laboratory populations of A. aquaticus (Panov 1988a) suggest that changes in the growth of adult isopods can be attributed to the direct influence of temperature, while the stunted growth of juveniles observed at low temperatures was most likely due to inappropriate food (low abundance of sessile bacteria and algae). Also, the growth rates of juvenile A. aquaticus in natural habitats were more affected by food than were the growth rates of adults, as were those of smaller bodied Asellus forbesi. Although Winberg (1987) suggested that the direct effects of temperature on developmental processes in poikilotherms can be properly studied only on life stages without external feeding, we are confident that in our experiments, food availability had no demonstrable effects on the growth of $H$. azteca and adult $A$. aquaticus. This supposition is supported by the ad libitum feeding regimen we used and by the fact that there was a good linear relationship between specific growth rates $(G)$ and mean body mass $\left(W^{-1 / b}\right)$ in these animals $\left(r^{2}>0.9\right)$.

Food availability, then, is extremely important and may have caused difficulties with the interpretation of earlier results. For example, it seems likely that the decrease in size of mayflies at low experimental temperatures or in cold environments (Sweeney and Vannote 1978; Vannote and Sweeney 1980) may have been due to inappropriate feeding conditions (see Atkinson 1994). Thus, the thermal equilibrium hypothesis proposed by Vannote and Sweeney (1980), which suggests that there is a quasi-equilibrium between the positive effect of increasing temperature on size and the negative effect of increasing size on mass-specific metabolism, may not provide a general explanation for the evolution of a phenological pattern in aquatic insects (Hawkins 1986) and the latitudinal differences in size of poikilotherms.

A negative size-temperature relationship often results in larger sizes of overwintering females in natural populations of freshwater aquatic insects (Sweeney 1978), isopods (Panov 1988a), and amphipods (H. azteca in this study). Because fecundity is generally positively related to body size (the relationship between fecundity and size for $H$. azteca is described by a power function), low winter temperatures maximize the reproductive potential of the overwintering population and lead to the production of a strong first generation in the early summer.

We also suggest that the optimal thermal regime for a population (where all life-history characteristics are important) is different from that producing maximum individual size and fecundity (sensu Vannote and Sweeney 1980). As we showed above, the optimal temperature for individual growth is sizedependent and defined by maximum $K_{2}$. Theoretically, the largest females appear in the coldest habitats, but low temperatures limit the induction of reproduction and result in slow development times, so that intrinsic rates of population increase involve a balance between female body size and egg number on the one hand and reproductive periodicity and development time on the other (McLaren 1963). Thus, the geographic region where individual mass and fecundity are maximized is not necessarily the location of greatest subpopulation biomass, as has been hypothesized for aquatic poikilotherms by Vannote and Sweeney (1980).

Sukhanov (1979) suggested from theoretical considerations that animals capable of optimizing growth could migrate into cooler waters as they grew. This is reminiscent of the ongoing controversy over whether vertical migrations provide a metabolic advantage (McLaren 1963; Shmeleva and Zaika 1973; Zaika 1985; Lampert 1989; Loose and Dawidowicz 1994). Whether or not there is a metabolic advantage to be gained by migrating, benthic crustaceans do move on a seasonal basis. Mathias (1971) showed that large H. azteca in Marion Lake (British Columbia, Canada) migrated from the shallow littoral zone to 3-4 m deep habitats, and that migration occurred when the temperature in the shallow littoral zone increased to $20^{\circ} \mathrm{C}$.

We also saw these patterns in Mouse Lake, where $H$. azteca was normally restricted to the shallow littoral zone (depth $>1 \mathrm{~m}$ ), but large adults moved to $3.5 \mathrm{~m}$ depth in July, when the temperature exceeded $25^{\circ} \mathrm{C}$. In most lakes, extensive seasonal migrations of large amphipods to open, deep habitats is likely to be constrained by an increased risk of fish predation due to the loss of the macrophyte cover that is associated with increasing water depth. Ranger Lake is an example. During our study, piscivore abundance was low (Demers 1996), pumpkinseed (Lepomus gibbosus) abundance was high, and H. azteca was not found in deep water. At Mouse Lake, however, piscivore abundance was high, pumpkinseed abundance was low, and amphipod migrations to open areas were possible. In the shallow littoral zone of both lakes, amphipods showed predator-avoidance behavior and concentrated in habitats with the lowest risk of fish predation. This behavior was associated with size-specific mortality rates that were the same at all sites (V.E. Panov, unpublished data). We suggest that at the comparatively low risk of fish predation in Mouse Lake in 1994 and in Marion Lake during Mathias' (1971) studies, temperature-induced migrations of large adult H. azteca in deep, cold habitats are possible.

Aksnes and Giske (1990) concluded from a theoretical analysis of habitat profitability that increases in environmental temperature may be more beneficial for marine copepods than the same relative decrease in predation-mediated mortality risk. This analysis was based on the strong negative relationship between generation (development) time $(T)$ and temperature (or a positive relationship between development rate $(1 / T)$ and temperature) in copepods. They suggested that in some copepods, optimal habitat choice should be more influenced by a relative change in temperature than an equal change in predation risk.

Decreasing development rates in large ectothermic animals at high temperatures can also result in migration to cooler habitats despite the increasing predation risk. This may have been the case for the H. azteca populations from Marion and Mouse lakes (noted above). Development rates in the largest H. azteca (Fig. 10) in natural populations, growing from 0.60 to $0.64 \mathrm{~mm}$ head length, reach their maximum at $20^{\circ} \mathrm{C}$. At temperatures above $20^{\circ} \mathrm{C}$, both development rates and $K_{2}$ values for this size group became lower and this may 
Fig. 10. Relationship between development rate (1/T) and net growth efficiency $\left(K_{2}\right)$ in large adult Hyalella azteca and temperature (see the text for details).

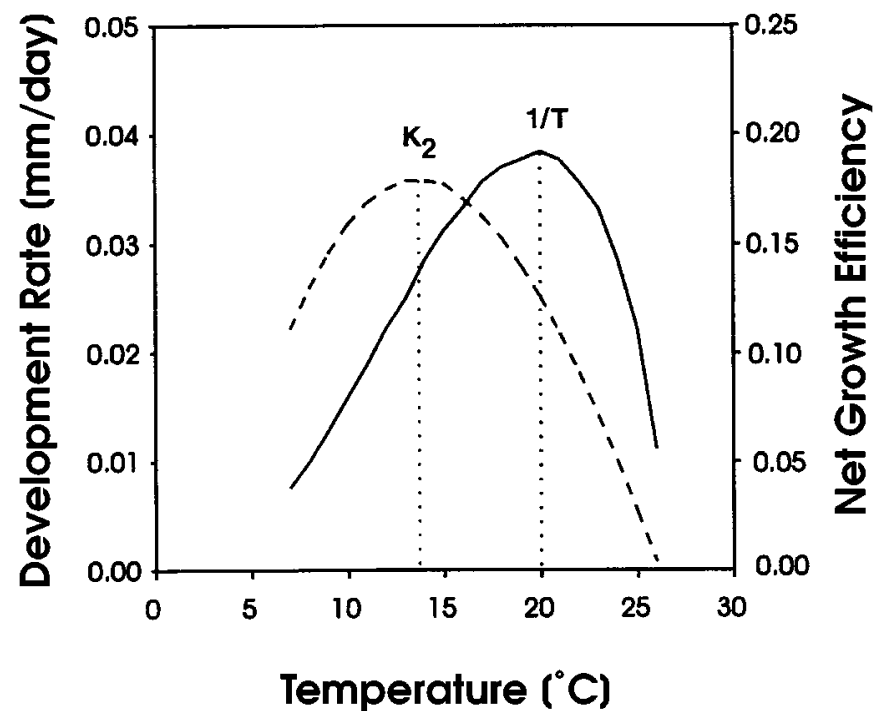

have caused temperature-induced migration. The optimal temperature for these large $H$. azteca is $14^{\circ} \mathrm{C}$, defined by maximum $K_{2}$ (Fig. 10), and similar temperatures were recorded at depths between 3 and $4 \mathrm{~m}$ in both Marion and Mouse lakes when migration of adult $H$. azteca from the shallow littoral zone occurred.

It has recently been shown that lakes with centrarchid fish contain small-bodied H. azteca and fishless ponds and marshes contain large-bodied individuals. Wellborn (1994) suggested that these differences in sizes are most likely (according Wellborn's data) to be genetically based. The literature on $H$. azteca functional ecology, including our study, deals only with amphipods from lake populations. In future it would be interesting to conduct studies to assess temperature effects on the energy budgets of large-bodied H. azteca not found in lakes.

\section{Acknowledgments}

We are grateful to I. Ostrovsky, and N. Perrin for valuable comments on the manuscript. Thanks are extended to $\mathrm{B}$. Clark for assistance in preparing figures and to D. Atkinson and a second anonymous reviewer for their comments. This study was supported by the Natural Sciences and Engineering Research Council of Canada (Grant ISE 0150664) and the Russian Fund for Basic Research (Grants 96-04-48109 and 96-15-97875) and was carried out with the assistance of the staff at the Ontario Ministry of Environment and Energy Dorset Research Centre.

\section{References}

Aksnes, D.L., and Giske, J. 1990. Habitat profitability in pelagic environments. Mar. Ecol. Prog. Ser. 64: 209-215.

Atkinson, D. 1994. Temperature and organism size-a biological law for ectotherms? Adv. Ecol. Res. 25: 1-58.

Atkinson, D., and Silby, R.M. 1996. On the solutions to a major life history puzzle. Oikos, 77: 359-365.
Berrigan, D., and Charnov, E.L. 1994. Reaction norms for age and size at maturity in response to temperature: a puzzle for life historians. Oikos, 70: 474-478.

Borgmann, U., and Munavar, M. 1989. A new standardized sediment bioassay protocol using the amphipod Hyalella azteca (Saussure). In Environmental bioassay techniques and their application. Developments in hydrobiology 54. Edited by M. Munawar, G. Dixon, C.I. Mayfield, T. Reynoldson, and M.H. Sadar. Kluwer Academic Publishers, Dordrecht, the Netherlands. pp. 425-431.

Bousfield, E.L. 1958. Fresh-water amphipod crustaceans of glaciated North America. Can. Field-Nat. 72: 55-113.

Brett, J.R., Shelbourn, J.E., and Shoop, C.T. 1969. Growth rate and body composition of fingerling sockeye salmon, Oncorhynchus nerka, in relation to temperature and ration size. J. Fish. Res. Board Can. 26: 2363-2394.

Chen, C.Y., and Folt, L.L. 1996. Consequences of fall warming for zooplankton overwintering success. Limnol. Oceanogr. 41: 10771086

Cooper, W.E. 1965. Dynamics and production of a natural population of a fresh-water amphipod, Hyalella azteca. Ecol. Monogr. 35: 337-394.

de March, B.G.E. 1977. The effects of photoperiod and temperature on the induction and termination of reproductive resting stage in the freshwater amphipod Hyalella azteca (Saussure). Can. J. Zool. 55: 1595-1600.

de March, B.G.E. 1978. The effects of constant and variable temperatures on the size, growth, and reproduction of the freshwater amphipod Hyalella azteca (Saussure). Can. J. Zool. 56: 18011806.

De Stasio, B.T., Jr., Hill, D.K., Kleinhans, J.M., Nibbelink, N.P., and Magnuson, J.J. 1996. Potential effects of global climate change on small north-temperate lakes: physics, fish, and plankton. Limnol. Oceanogr. 41: 1136-1149.

Downing, J.A. 1979. Aggregation, transformation, and the design of benthos sampling programs. J. Fish. Res. Board Can. 36: 1454 1463.

Demers, E. 1996. Role of predation in structuring fish communities. Ph.D. thesis, York University, Toronto, Canada.

Elliott, J.M., and Davison, W. 1975. Energy equivalents of oxygen consumption in animal energetics. Oecologia, 19: 195-201.

Embody, G.C. 1911. A preliminary study of the distribution, food and reproductive capacity of some fresh-water amphipods. Int. Rev. Ges. Hydrobiol. Hydrogeogr. (Suppl.), 4: 1-33.

Ernsting, G. 1995. Ectotherms, time and temperature: reaction norms for age and size at maturity. Oikos, 72: 444-445.

Ernsting, G., Zonneveld, C., Isaaks, J.A., and Kroon, A. 1993. Size at maturity and patterns of growth and reproduction in an insect with indeterminate growth. Oikos, 66: 17-26.

Geisler, F.S. 1944. Studies on the postembryonic development of Hyalella azteca (Saussure). Biol. Bull. (Woods Hole, Mass.), 86: 6-22.

Hairston, N.G., Jr. 1996. Zooplankton egg banks as biotic reservoirs in changing environments. Limnol. Oceanogr. 41: 10871092.

Halat, K.M., and Lehman, J.T. 1996. Temperature-dependent energetics of Chaoborus populations: hypothesis for anomalous distributions in the great lakes of East Africa. Hydrobiologia, 330: 31-36.

Hanazato, T. 1989. Effect of temperature in laboratory studies on growth of Chaoborus flavicans (Diptera: Chaoboridae). Arch. Hydrobiol. 114: 497-504.

Hanazato, T. 1991. Effects of a Chaoborus-released chemical on Daphnia ambigua: reduction in the tolerance of the Daphnia to summer water temperature. Limnol. Oceanogr. 36: 165-171.

Hawkins, C.P. 1986. Variation in individual growth rates and population densities of ephemerellid mayflies. Ecology, 67: 13841395. 
Hogg, I.D., and Williams, D.D. 1996. Response of stream invertebrates to a global-warming thermal regime: an ecosystem-level manipulation. Ecology, 77: 395-407.

Kooijman, S.A.L.M. 1993. Dynamic energy budgets in biological systems. Cambridge University Press, Cambridge.

Kozlowski, J. 1992. Optimal allocation of resources to growth and reproduction: implications for age and size at maturity. Trends Ecol. Evol. 7: 15-19

Lampert, W. 1989. The adaptive significance of diel vertical migration of zooplankton. Funct. Ecol. 3: 21-27.

Loose, C.J., and Dawidowicz P. 1994. Trade-offs in diel vertical migration by zooplankton: the costs of predator avoidance. Ecology, 75: 2255-2263.

Lozano, S.J., and Kitchell, J.K. 1978. Response of a mobile invertebrate to heterothermal conditions. In Energy and Environmental Stress in Aquatic Systems: Proceedings of a Department of Energy Symposium, Augusta, Ga., November 2-4, 1977. Edited by J.H. Thorp and J.W. Gibbons. pp. 511-520.

Mathias, J.A. 1971. Energy flow and secondary production of the amphipods Hyalella azteca and Crangonyx richmondensis occidentalis in Marion Lake, British Columbia. J. Fish. Res. Board Can. 28: 711-726.

McDonald, M.E., Hershey, A.E., and Miller, M.C. 1996. Global warming impacts on lake trout in arctic lakes. Limnol. Oceanogr. 41: $1102-1108$.

McLaren, I.A. 1963. Effects of temperature on growth of zooplankton and the adaptive value of vertical migration. J. Fish. Res. Board Can. 20: 685-727.

Metz, J.A.J., and Diekmann, O. 1986. (Editors). The dynamics of physiologically structured populations. Lect. Notes Biomath. No. 68.

Mladenova, A.G. 1991. Individual production and metabolism in isopod Asellus aquaticus L. under different temperature and food conditions. [In Russian.] Ph.D. thesis, Zoological Institute, Leningrad.

Mladenova, A. 1993. Importance of the temperature for the energetic metabolism of fresh-water isopod [Asellus aquaticus (L.)]. Zh. Ekol. [J. Aquat. Ecol.] 2(1): 55-63.

Moore, D.W., and Farrar, J.D. 1996. Effect of growth on reproduction in the freshwater amphipod, Hyalella azteca (Saussure). Hydrobiologia, 328: 127-134.

Panov, V.E. 1986. Growth and production of Asellus aquatucus (L.) (Isopoda) in the littoral zone of the Neva Bay of the Gulf of Finland. [In Russian.] Proc. Zool. Inst. Leningr. 152: 142-161.

Panov, V.E. 1988a. Growth of Asellus aquaticus (L.): structure and production of populations. [In Russian.] Proc. Zool. Inst. Leningr. 186: $53-73$.

Panov, V.E. 1988b. Amphipod growth and production. [In Russian.] Proc. Zool. Inst. Leningr. 186: 150-160.

Panov, V.E., and Pavlov, A.M. 1986. Method of counting aquatic invertebrates in beds of bulrush and reed. Hydrobiol. J. 22(6): $87-88$.

Pennak, R.W. 1953. Fresh-water invertebrates of the United States. Ronald Press Co., New York. pp. 435-446.

Perrin, N. 1995. About Berrigan and Charnov's life-history puzzle. Oikos, 73: 137-139.

Ray, C. 1960. The application of Bergmann's and Allen's rules to the poikilotherms. J. Morphol. 106: 85-108.

Sevenster, J.G. 1995. Equations or organisms? A comment on Berrigan and Charnov. Oikos, 73: 405-407.

Shmeleva, A.A., and Zaika, V.E. 1973. Vertical distribution of copepodite stages of the Adriatic Sea copepods. [In Russian.] Oceanology, 13: 872-876.

Stearns, S.C. 1989. Trade-offs in life-history evolution. Funct. Ecol. 3: $259-268$.
Stearns, S.C. 1992. The evolution of life histories. Oxford University Press, Oxford.

Stearns, S.C., and Koella, J. 1986. The evolution of phenotypic plasticity in life-history traits: predictions of reaction norms for age and size at maturity. Evolution, 40: 893-913.

Steele, D.H., and Steele, V.J. 1975. The biology of Gammarus (Crustacea: Amphipoda) in the northwestern Atlantic. XI. Comparison and discussion. Can. J. Zool. 53: 1116-1126.

Strong, D.R. 1972. Life history variation among populations of an amphipod (Hyalella azteca). Ecology, 53: 1103-1111.

Strong, K.W., and Daborn, G.R. 1979. Growth and energy utilisation of the intertidal isopod Idotea baltica (Pallas) (Crustacea: Isopoda). J. Exp. Mar. Biol. Ecol. 41: 101-123.

Strong, K.W., and Daborn, G.R. 1980. The influence of temperature on energy budget variables, body size, and seasonal occurrence of the isopod Idotea baltica (Pallas). Can. J. Zool. 58: 1992-1996.

Sukhanov, V.V. 1979. Growth of poikilothermic animals under the influence of temperature and food environmental conditions. [In Russian.] Biol. Morja (Vladivost.), 4: 6-13.

Sweeney, B.W. 1978. Bioenergetic and developmental response of a mayfly to thermal variation. Limnol. Oceanogr. 23: 461-477.

Sweeney, B.W. 1984. Factors influencing life-history patterns of aquatic insects. In Ecology of aquatic insects. Edited by V.H. Resh and D. Rosenberg. Praeger Scientific, New York. pp. 56-100.

Sweeney, B.W., and Vannote, R.L. 1978. Size variation and the distribution of hemimetabolous aquatic insects: two thermal equilibrium hypotheses. Science (Washington, D.C.), 200: 444-446.

Sweeney, B.W., and Vannote, R.L. 1986. Growth and production of a stream stonefly: influences of diet and temperature. Ecology, 67: $1396-1410$

Sweeney, B.W., Vannote, R.L., and Dodds, P.J. 1986. Effects of temperature and food quality on growth and development of a mayfly, Leptophlebia intermedia. Can. J. Fish. Aquat. Sci. 43: 12-18.

Sweeney, B.W., Jackson, J.K., Newbold, J.D., and Funk, D.H. 1991. Climate change and the life histories and biogeography of aquatic insects in eastern North America. In Global climate change and freshwater ecosystems. Edited by P. Firth and S.G. Fisher. Springer-Verlag, New York. pp. 143-167.

Thompson, P.J. 1986. Heritability for body size in the isopod Asellus aquaticus (L.). Crustaceana (Leiden), 51: 241-244.

Threlkeld, S.T. 1979. The midsummer dynamics of two Daphnia species in Wintergreen Lake, Michigan. Ecology, 60: 165-179.

Vannote, R.L., and Sweeney, B.W. 1980. Geographic analysis of thermal equilibria: a conceptual model for evaluating the effect of natural and modified thermal regimes on aquatic insect communities. Am. Nat. 115: 667-695.

von Bertalanffy, L. 1960. Principles and theory of growth. In Fundamental aspects of normal and malignant growth. Edited by W.N Nowinski. Elsevier, Amsterdam. pp. 137-259.

Wellborn, G.A. 1994. Size-biased predation and prey life histories: a comparative study of freshwater amphipod populations. Ecology, 75: $2104-2117$.

Winberg, G.G. 1983. Van't-Hoff's temperature coefficient and Arrenius' equation in biology. [In Russian.] J. Gen. Biol. (Mosc.), 44: $31-42$.

Winberg, G.G. 1987. The dependence of ontogenetic development from temperature. [In Russian.] In Production-biological investigations of aquatic ecosystems. Edited by A.F. Alimov. Nauka, Leningrad. pp. 5-34

Zaika, V.E. 1985. The balance theory of animal growth. [In Russian.] Naukova Dumka Publishers, Kiev.

Zhemaeva, N.P. 1987. Structure of Asellus population in the pond culture. [In Russian.] Gidrobiol. J. 23(1): 95-99. 